\title{
Assessing South African ICT4D research outputs: A journal review
}

\author{
Marita Turpin \\ Department of Informatics, University of Pretoria, South Africa
}

\begin{abstract}
South Africa is an ideal test bed for ICT4D research, since on the one hand it has stark development challenges, and on the other hand it has well established ICT infrastructure that could be utilised towards socio-economic development. Not surprisingly, a plethora of ICT4D projects are executed in South Africa by a variety of roleplayers. This paper focuses on how effective South African researchers are in converting ICT4D research activity into significant research outputs. Since effective research is assessed by journal publications, a review was done of papers published by South African authors in the prominent international ICT4D journals. It is found that while South Africa has a prominent presence in ICT4D journals, this prominence is concentrated in one research institution and one ICT4D journal. A surprising finding is that cooperation among research institutions that leads to co-authored publications is very low, even among neighbouring institutions. Future research is suggested to investigate the good practices of the most prolific research institution, to investigate reasons for the low cooperation between institutions and to more thoroughly investigate the research contributions made by the South African authors.
\end{abstract}

Keywords: ICT4D research, ICT4D literature survey, South Africa

Categories: • General reference $\sim$ Surveys and overviews

Email:

Article history:

Marita Turpin marita.turpin@up.ac.za (CORRESPONDING)

\section{Received: 23 September 2017}

Accepted: 29 January 2018

Available online: 10 July 2018

\section{INTRODUCTION}

South Africa is an ideal test bed for ICT4D research. On the one hand, it is burdened with severe socio-economic challenges such as extreme inequality (The World Bank, 2017) and an unemployment rate of above 36\% when discouraged work-seekers are included (StatsSA, 2017). On the other hand, South Africa has well established ICT infrastructure covering large parts of the country, and a high rate of mobile phone uptake (ITWeb, 2016). Hence it is not surprising that a plethora of ICT4D projects can be found: government, research institutions, private companies, international aid organisations as well as various nongovernmental organisations (NGOs) run projects that attempt to provide ICT related infrastructure, services and training to improve socio-economic conditions. Along with the ICT4D activity, there is an increased interest in

Turpin, M. (2018). Assessing South African ICT4D research outputs: A journal review. South African Computer Journal 30(1), 108-127. https://doi.org/10.18489/sacj.v30i1.541

Copyright (C) the author(s); published under a Creative Commons NonCommercial 4.0 License (CC BY-NC 4.0). $S A C J$ is a publication of the South African Institute of Computer Scientists and Information Technologists. ISSN 1015-7999 (print) ISSN 2313-7835 (online). 
ICT4D research. In recent years, a number of ICT4D workshops were held at conferences such as the Southern African Institute for Computer Scientist and Information Technologists (SAICSIT) Annual Conferences of 2014 and 2015, and the International Development Informatics Association (IDIA) conference of 2014. At the workshops, the research institutions who attended reported on an impressive array of ICT4D initiatives. During the workshops it became clear that most of the large universities in South Africa have ICT4D research groups that are busy expanding. The projects presented by the research groups appeared to be increasing in variety and sophistication, for example by paying more attention to stakeholder engagement and having improved monitoring and evaluation (M\&E) functionality.

At one of the ICT4D workshops a central problem was identified: it was not clear whether the large amount of ICT4D activities undertaken by academic institutions led to research outputs that did them justice. At the SAICSIT 2014 ICT4D workshop, Geoff Walsham made the remark that while he was impressed by the number of ICT4D projects, he did not notice strategic thinking around research programmes that included a publication strategy, leading to research outputs. As he later repeated, thinking about one's research outputs is necessary to achieve a publication impact (Walsham, 2017). Geoff, who was a keynote speaker at the SAICSIT conference, is an ICT4D veteran who has had a relationship with South Africa's ICT4D community for many years. He was qualified to make the remark, and workshop participants were observed responding in agreement.

This paper is an attempt to assess the state of ICT4D research in South Africa, and provide a response to Geoff's remark. Are South Africa's ICT4D research activities leading to commensurate research outputs? Are the innovations, failures, success stories, reflections and lessons learned made visible, on recognised ICT4D dissemination platforms? The research question underlying this study is the following:

What is the state of ICT4D publications by South African ICT4D researchers?

The study is performed by means of a literature review, to see what is being published by South African ICT4D researchers. The review is performed on three journals dedicated to ICT4D, namely Information Technology for Development (ITD), Information Technologies and International Development (ITID), and the Electronic Journal on Information Systems in Developing Countries (EJISDC). Ten years of publications in these journals (2006 - 2015) are searched for contributions by South African authors. The papers found are analysed in terms of their numbers, affiliation of authors, co-authorship, topics covered and empirical locations of studies.

The paper is structured as follows. First, some background is given on previous reviews in the ICT4D field. The subsequent section contains the research planning. Following this is a discussion of the results of the literature review. Finally, the conclusion reflects on research findings and the implications of these for South African ICT4D research. 


\section{BACKGROUND: PREVIOUS REVIEWS OF ICT4D LITERATURE}

A number of review studies have recently been performed in ICT4D (Avgerou, 2010; Gitau, Plantinga, \& Diga, 2010; Walsham, 2010; Dodson, Sterling, \& Bennett, 2013; Gomez, 2013; Andersson \& Hatakka, 2013; K.A. Johnston, Jali, Kundaeli, \& Adeniran, 2015; Ghosh, Mudavanhu, \& Belle, 2015; Naudé, 2016b, 2016a). Some of them have a particular South African (K.A. Johnston et al., 2015) or African (Gitau et al., 2010; Thompson \& Walsham, 2010) focus. Previous review studies are briefly investigated here in order to learn from their content as well as their method.

Avgerou's "Discourses on ICT and Development" presents a general review of ICT4D literature (2010). It maps the ICT4D research landscape according to authors' assumptions on how ICT innovation takes place, as well as on what constitutes socio-economic development. Avgerou indicates how the two sets of assumptions lead to four different discourses in ICT4D. Avgerou states which publications were included in her study, but she does not supply further details such as time periods or methods of analysis. Gomez performs an encompassing review of ICT4D literature over the period 2000-2010 (2013). The Gomez study analyses 948 papers obtained from five ICT4D journals as well as two conferences. Papers were classified according to a number of themes, such as research methods, application domain, type of technology used, and geographic distribution of studies. Key findings include evidence of growth in the maturity of the field, as well as shifts in the type of technology studied and research approaches. An inter-journal comparison is also done.

Some review studies focus on a particular publication avenue. For example, the papers in Information Technologies and International Development (ITID) were studied for the period 20032010 to see whether the projects that were reported on met their stated development objectives (Dodson et al., 2013). It was found that certain approaches (bottom-up as opposed to topdown, and community-centric vs. technology-centric) could be associated with project success, whereas the opposite approaches were more likely to lead to failure. In another publication specific review, the annual conferences of the International Development Informatics Association (IDIA) were studied for the period 2011-2014 (Ghosh et al., 2015), mainly to see whether they have succeeded in their goal of providing a voice to researchers from the global South. It was found that while IDIA succeeded to attract the majority of their authors from the global South, the South's contribution was dominated by South Africans. The IDIA analysis also contains a brief classification of the papers into application domains, research methods and empirical locations (Ghosh et al., 2015). Similarly, the biennial conferences of IFIP WG 9.4 were analysed by Gallivan and Tao (2013) for the period 2002-2013. Gallivan and Tao performed a longitudinal study that focused on frequent contributions by authors, institutions and countries as well as frequently occurring topics. In this analysis, South Africa appears as the fourth most productive country at the IFIP WG 9.4 conference during the period 2002-2014, as well as the most productive developing country.

A bibliometric analysis of the Electronic Journal of Information Systems in Developing Countries (EJISDC) is done by Naudé for the period 2000 - 2013 (2016b, 2016a). In the first of these 
two papers, Naudé investigates a few basic characteristics of EJISDC papers such as their average length and number of references and citations. However the main contribution of Naudés first study is an analysis of EJISDC authors, author productivity, author institutions and collaboration. The study finds that the University of Cape Town (UCT) in South Africa is the most productive institution in terms of EJISDC publications during the period surveyed, and that two of the five most productive authors are from South Africa. Naudé's finding on collaboration is that most papers in EJISDC are co-authored, and the most prevalent form of collaboration is between authors from the same institution (2016b). In the second part of Naudé's bibliometric review of EJISDC, she investigates country productivity and continues the collaboration analysis started in the first article (2016a). Country productivity indicates South Africa as the fourth most productive country by articles and the fifth most productive by author. In terms of the co-authorship or collaboration analysis, there are no findings of particular interest about South Africa. To conclude, Naudé's two studies of the EJISDC journal contains findings of potential relevance to this study. The publication focused reviews discussed above all conclude with an introspection of their own journal/conference as well as a reflection on ICT4D research - as found in their publication.

Another way that systematic reviews in ICT4D are presented is by a particular topic. For example, Andersson and Hatakka did a review of theories used in ICT4D research (2013). They reviewed the journals ITD, ITID and EJISDC for all empirical papers from 2005 - 2012. They find that theories that investigate the adoption, uptake and resistance of technology are the most prevalent, and conclude that such theories are not the most appropriate to apply in ICT4D. An example of a thematic review closer to home is K.A. Johnston et al. (2015)'s analysis of South African ICT4D studies that focus on specific socio-economic development topics. They use Walsham (2010)'s categorisation of development aims and reviews a set of papers that explicitly address those aims. Although K.A. Johnston et al. (2015)'s study has a South African focus, it is not relevant to this study because of its different purpose.

Findings from the literature review of ICT4D reviews that are relevant to this study include the following: The review of IDIA conferences found that South Africa is a dominant contributor (Ghosh et al., 2015), and the review of EJISDC found that a South African institution is the most prolific institution (Naudé, 2016b). The review of IFIP WG 9.4 conferences found that South Africa is the most productive developing country and the fourth most productive overall. The South African presence at IDIA could be explained by the fact that the conference was founded by a South African and is organised mainly by South Africans; in addition four of the nine IDIA conferences that were held to date were hosted in South Africa (IDIA, n.d.). At the same time, the fact that South Africans contributed to establish a regular international ICT4D conference is evidence of South Africa's influence on the international ICT4D stage. The EJISDC journal, in which a South African institution has a prominent presence, is one of the top international ICT4D publications (Heeks, 2010) and is not controlled by South Africans in any way. The same can be said for the IFIP WG 9.4 conferences that have a high international standing. What these findings indicate to us, is potential grounds to challenge Walsham's remark on the lack of a strategic research focus related to ICT4D publications by South Africans. These grounds will 
be further investigated in the survey that follows. The next section explains and motivates how the review of South African ICT4D publications was performed.

\section{RESEARCH STRATEGY}

The aim of the study is to assess how well South African ICT4D researchers have progressed in disseminating the research outputs associated with ICT4D research projects, into recognised publication outlets. The ability to disseminate their research implies that they followed an appropriate research process, from planning through execution to analysing results. We ask the following question:

What is the state of ICT4D publications by South African ICT4D researchers?

Doing justice to this question is a challenge. ICT4D is a multidisciplinary field and research could be published in journals related to ICT4D, Information Systems, Information Technology, Community Informatics, Development Studies or any of the domain areas where ICT was applied, such as health, government or education, to name a few. Research outputs may also be found in the form of conference talks/papers, reports or artefacts. To make the scope of the study manageable, it will be limited to journal papers. In particular, it will be limited to the following ICT4D journals: Information Technology for Development (ITD), the Electronic Journal of Information Systems in Developing Countries (EJISDC), and Information Technologies and International Development (ITID). These journals are the ones recognised in other ICT4D research reviews (Avgerou, 2010; Andersson \& Hatakka, 2013; K.A. Johnston et al., 2015). While South Africans may have published their work in South African or African journals, none of the local or regional journals are exclusively dedicated to ICT4D, and neither are the ICT4D papers that appear in those journals necessarily categorised as such. Hence, if journals other than the above mentioned ICT4D journals are included, it will be a difficult task to select which of their articles to include in the study and which not. Further, it is expected that the ICT4D journals mentioned above will form part of South African ICT4D researchers' publication strategies.

In order to get a sufficient overview as well as a time trend, a search was done for the 'South African' papers in each of these journals over the 10 year period of 2006 - 2015 .

\subsection{What was counted as a 'South African' paper?}

Deciding which papers to include as 'South African' was not straightforward. If a study was done by South African authors in a South African case setting, it was an easy decision. However, South African researchers also perform ICT4D research in other countries. Further, a number of studies undertaken in South Africa are published by non-South Africans. When a visiting researcher is based for a few months at a South African institution and acknowledges that institution by means of a second affiliation, without co-authoring anyone from the same institution, does that count as a 'South African' paper? To deal with these grey areas in a consistent manner, the rules for inclusion were as follows: 
- A paper with at least one South African co-author (a person whose first affiliation is an institution or place in South Africa); and

- The empirical setting had to include (but not be limited to) South Africa. For theoretical or conceptual papers, this rule was not applied; and

- Full research papers and research reports were included, but not practitioner reports. The three journals had slightly different phrases for categorising papers in essentially the same manner.

Applying these criteria means that a paper written by South Africans about research in Botswana was not included, but a study with authors from South Africa and Botswana, comparing settings in South Africa and Botswana, was counted. Research done by non-South Africans was not counted, because there was no evidence of local research capacity being involved. The aim of this study is to provide an assessment of South Africans' own ICT4D research ability, which includes making a difference in, as well as studying and understanding their own country. To acknowledge the subjectivity in the review inclusion criteria, 'South African' paper is written in parentheses in this article.

The search was performed for the period 2006 - 2015 (January 2006, up to 31 December 2015). In this period, ITD has always had one volume and four issues per year, ITID followed the same pattern most of the years, and EJISDC did not limit themselves to four issues. Being an online journal not limited by printing costs, they published more issues during times when they had more papers submitted and accepted, so that their number of issues per year varied between three and six. Also, EJISDC had slightly more research articles per issue than the other two journals. It is estimated that ITD and ITID published similar amounts of papers in the period studied, and EJISDC almost double that amount.

\section{RESEARCH RESULTS}

The number of 'South African' papers found in each of the three journals in the ten year review period is shown in Table 1 and Figure 1 below.

There is an overall upward trend in number of publications over the 10 year period, however, this is predominantly due to the contribution of the EJISDC papers. In 2015, ITD had two special issues on Africa, leading to the unusually high number of seven South African papers in ITD in one year. Looking at the overall picture, the total number of 'South African' papers in EJISDC far outweighs the number of papers in ITD and ITID. In the research strategy section, it was mentioned that EJISDC sometimes published more than four issues per year during the 10 year period, as well as more research papers per issue, compared to the other two journals. However, EJISDC published perhaps double but not four times as many papers as the other two journals over this period. Also, during the literature search, the ratio of South African papers to total number of papers per journal appeared to be higher for EJISDC than for the other two journals. 
Table 1: 'South African' ICT4D papers in three journals, 2006-2015

\begin{tabular}{ccccc}
\hline Year & EJISDC & ITD & ITID & Total \\
\hline 2006 & 1 & 0 & 0 & 1 \\
2007 & 1 & 1 & 1 & 3 \\
2008 & 0 & 2 & 1 & 3 \\
2009 & 3 & 1 & 0 & 4 \\
2010 & 1 & 0 & 1 & 2 \\
2011 & 3 & 1 & 2 & 6 \\
2012 & 10 & 1 & 0 & 11 \\
2013 & 1 & 2 & 0 & 3 \\
2014 & 7 & 0 & 0 & 7 \\
2015 & 10 & 7 & 1 & 18 \\
\hline Total & 37 & 15 & 6 & 58 \\
\hline
\end{tabular}

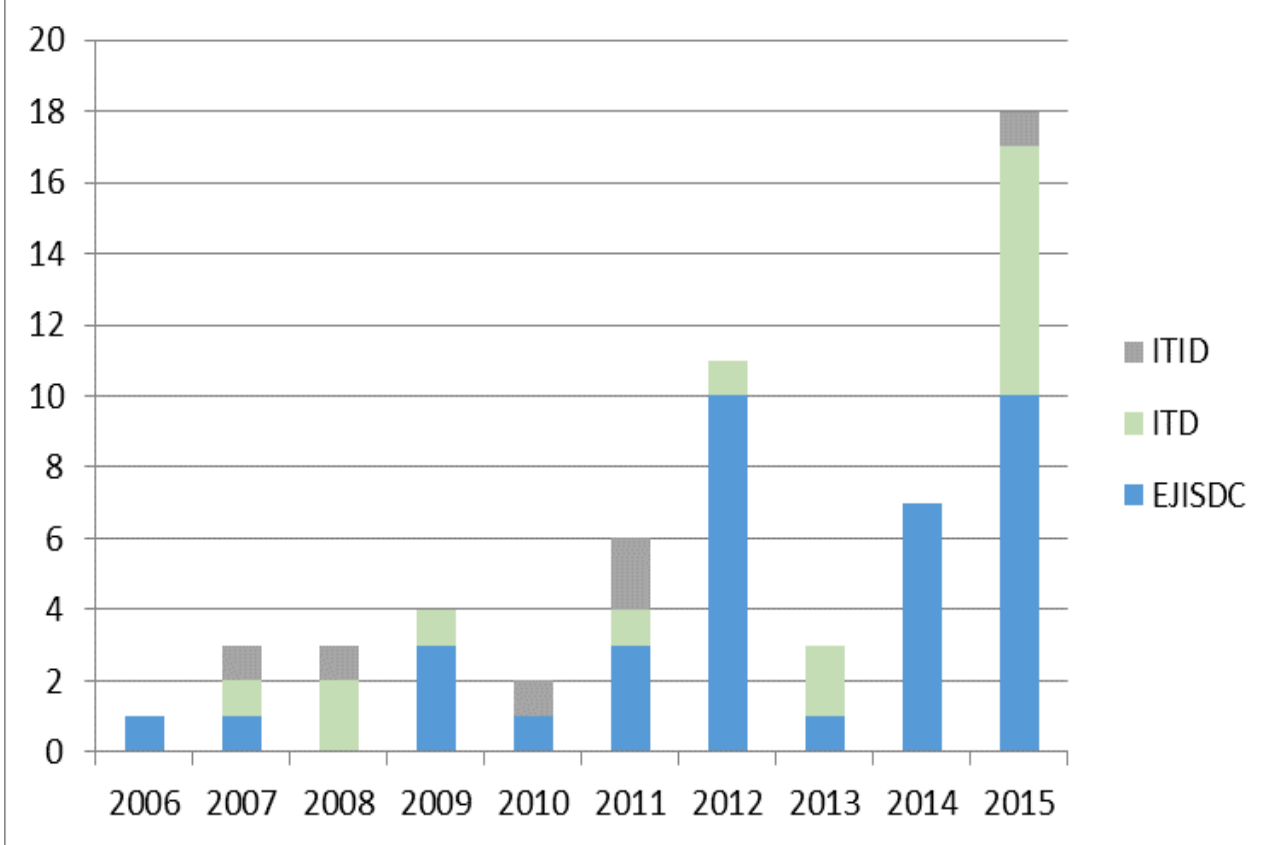

Figure 1: Bar chart of 'South African' ICT4D publications in three journals, 2006-2015 
This implies that while South Africans publish steadily in all three journals, EJISDC appears to be their ICT4D dissemination avenue of preference.

\subsection{Research papers per institution}

A point of interest while performing the review was the distribution of ICT4D publications among research institutions in South Africa. A variety of institutions were listed by authors as their affiliations, but the name of the University of Cape Town (UCT) seemed to appear more frequently on papers than the names of other institutions. This impression was confirmed when counting the papers per institution (see Table 2): UCT significantly outperforms the other institutions. The University of Pretoria, Rhodes University and Cape Peninsula University of Technology share the next level of publication proficiency. (Note that the total in the right hand column of Table 2 does not add up to the total in the previous table, since a paper was counted more than once if it had authors from more than one institution). Some papers had international co-authors, but since the focus is on South African authors, the affiliations of authors from international institutions are not included in Table 2. International authors are however included in the co-authorship analysis presented later in this paper.

In terms of preferences for journals, UCT appears to have a strong preference for EJISDC with 14 of their 20 papers published in EJISDC. A few other institutions show a similar preference, such as CPUT with all six of their publications in EJISDC. Likewise, Unisa, TUT, NMMU, Stellenbosch and UJ all have only published in EJISDC, but due to their small numbers of outputs one cannot draw conclusions from this.

\subsection{Research papers per geographical region}

Figure 2 shows a geographic clustering of research outputs, as indicated by the institutional affiliations of the authors (a paper was counted for a region if it included an author whose institution was from that region, so some papers were counted more than once). Figure 2 indicates a dominance by the Western Cape, the region with which authors of 31 papers are associated. The Western Cape grouping consists of four institutions namely UCT, CPUT, Stellenbosch and UWC. Of these, UCT is the dominant contributor. In the Gauteng region, the second largest concentration of authors can be found, namely 25. These 25 authors represent 10 different institutions, namely UP, Wits, CSIR, Monash SA, TUT, UJ, ICASA, Telkom SA and the two private authors. The third concentration of authors is in the Eastern Cape, namely 11. These 11 authors are affiliated with three institutions namely Rhodes, Fort Hare and NMMU. The fourth and smallest area of authorship is Kwa-Zulu Natal, with three authors from two institutions: UKZN and Zululand.

\subsection{Patterns in empirical settings}

Where in South Africa were the empirical studies performed? The intention for asking this question was to see whether some parts of the country benefited more than others, from ICT4D research attention. In particular, if a large percentage of ICT4D publications arise from Western 
Table 2: Authorship of 'South African' ICT4D publications in three journals, 2006-2015

\begin{tabular}{lcccc}
\hline SA Institution & EJISDC & ITD & ITID & Total \\
\hline University of Cape Town (UCT) & 14 & 3 & 3 & 20 \\
University of Pretoria (UP) & 3 & 4 & 0 & 7 \\
Cape Peninsula University of Technology (CPUT) & 6 & 0 & 0 & 6 \\
Rhodes University & 4 & 2 & 0 & 6 \\
Council for Scientific and Industrial Research (CSIR) & 1 & 2 & 1 & 4 \\
University of Fort Hare & 3 & 1 & 0 & 4 \\
University of the Western Cape (UWC) & 2 & 2 & 0 & 4 \\
University of South Africa (Unisa) & 3 & 0 & 0 & 3 \\
Monash University of South Africa & 1 & 1 & 0 & 2 \\
Tshwane University of Technology (TUT) & 2 & 0 & 0 & 2 \\
University of KwaZulu-Natal (UKZN) & 1 & 0 & 1 & 2 \\
Private & 1 & 1 & 0 & 2 \\
Witwatersrand University (Wits) & 0 & 1 & 1 & 2 \\
Independent Communications Authority & 0 & 0 & 1 & 1 \\
of South Africa (ICASA) & 1 & 0 & 0 & 1 \\
Nelson Mandela Metropolitan University (NMMU) & 1 & 0 & 0 & 1 \\
Stellenbosch University & 1 & 0 & 0 & 1 \\
Telkom SA & 1 & 0 & 0 & 1 \\
University of Johannesburg (UJ) & 0 & 1 & 0 & 1 \\
University of Zululand & & & & \\
\hline
\end{tabular}

Cape authors, do communities in the Western Cape receive proportionately more attention in the form of ICT4D research studies? To address this question, the empirical settings of the 52 papers with an empirical component were analysed.

Before proceeding, a disclaimer needs to be made: One cannot necessarily claim that all communities where empirical studies are performed, are 'benefiting'. Firstly, ICT4D projects do not always meet their development objectives (Dodson et al., 2013). Secondly, quite a few of the studies reviewed are descriptive or use secondary data; hence the authors were observers rather than interventionists. Yet, it is often the case that empirical studies go along with some sort of investment in a community, in terms of time spent to better understand conditions and user needs, and/or by providing interventions such as training, establishment of telecentres or the development of tailor made information systems. Hence, it is likely that people included in an empirical study benefit in some way - even if the projects do not meet their development objectives. To conclude: an analysis of empirical settings would indicate which areas receive more research attention, and are possibly benefitting from such ICT related interventions.

The geographic locations of the 52 papers that contain studies with empirical components are indicated per province in Table 3. Studies spanning multiple provinces were grouped along with national level studies.

Table 3 does not indicate in what kinds of settings the projects were performed (e.g., rural or peri-urban). Most of the studies took place in socio-economically disadvantaged settings, whether urban, peri-urban or rural. (A small number of studies do not address socio-economic concerns at all and are only published in ICT4D journals because South Africa is a developing country. 


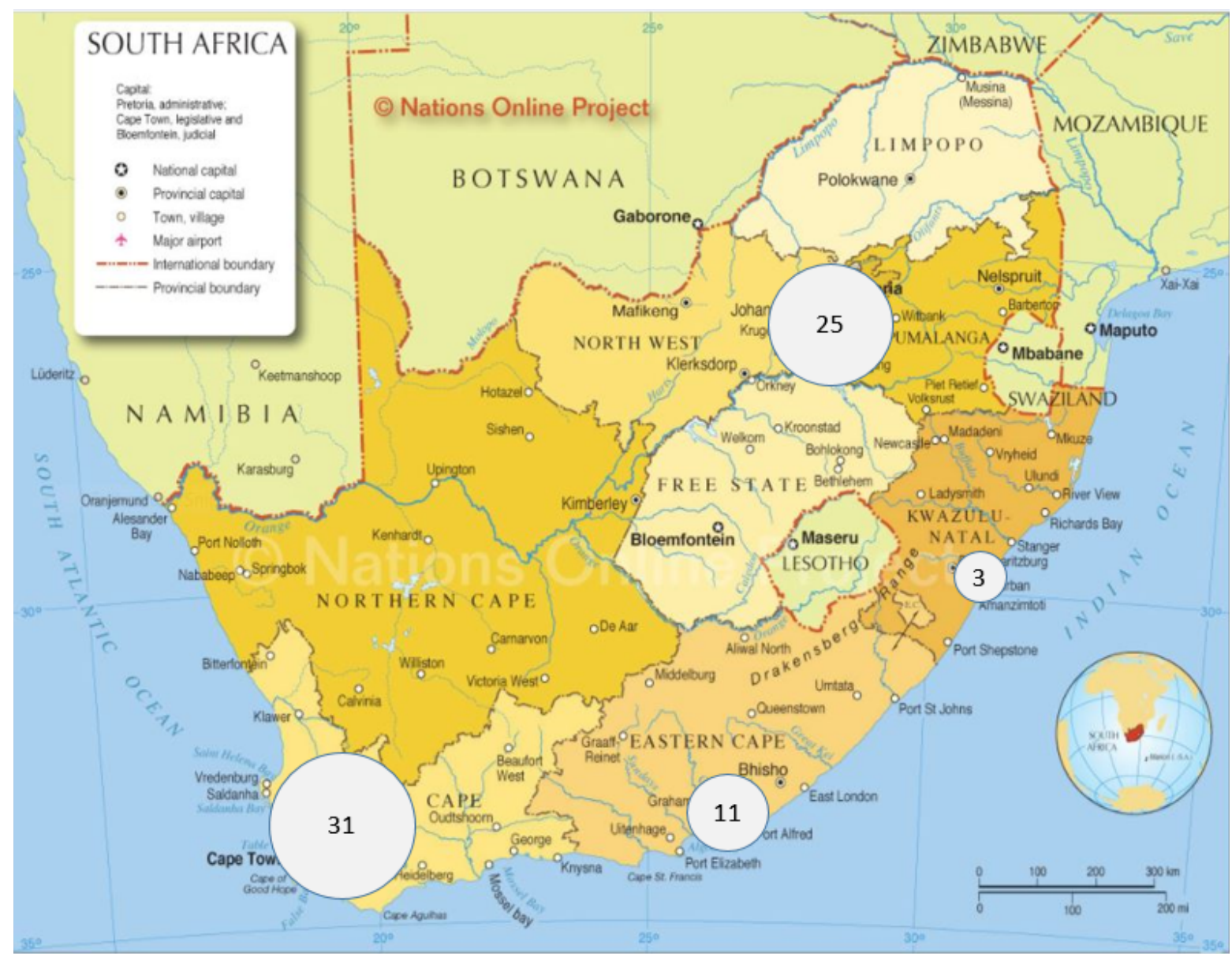

Figure 2: Research outputs per geographical region

However, these studies are few and will not be considered further in this section). In the Western Cape, most studies were conducted in the vicinity of Cape Town, often in disadvantaged townships. In the Eastern Cape, the settings were mostly rural, whereas in the other provinces the locations were distributed between rural and urban.

Since a large percentage of ICT4D papers are published by authors located in the Western Cape, it is not surprising that the Western Cape dominates the empirical picture. It makes sense to perform empirical work closer to home, taking into account the expense of travel time and cost. However, when comparing Table 3 with Figure 2, it is clear that quite a few studies are not limited to the authors' own locations. North West and KwaZulu-Natal are home to more studies than authors, in addition to which 14 studies are spanning provinces. A quick comparison between author locations and empirical study locations shows that while 24 of the 52 studies are limited to the province in which the authors reside, 28 studies span a wider geographic setting.

Most of the cross country studies have authors from multiple countries. However, the countries 
Table 3: Locations of empirical studies

\begin{tabular}{lc}
\hline Province or location & $\begin{array}{c}\text { No. of papers with empirical } \\
\text { study in location }\end{array}$ \\
\hline Western Cape & 14 \\
Eastern Cape & 7 \\
Gauteng & 4 \\
KwaZulu-Natal & 4 \\
North West & 1 \\
Multi-province or National & 14 \\
Multiple countries (incl. SA) & 8 \\
\hline Total & 52 \\
\hline
\end{tabular}

included in the studies often span wider than the locations of the authors.

To conclude, the analysis of empirical settings indicate that while the Western Cape benefits from research attention more so than the other provinces due to author location, more than half of the authors do not limit themselves to studies close to their homes.

\subsection{Research domains}

This section contains a classification of the 'South African' ICT4D papers into research domains. The exercise was anticipated to be straightforward but proved quite challenging, as there was no pre-existing classification scheme within which the work of South African researchers neatly fitted. A sectoral classification with categories such as health, education and agriculture proved inadequate - the application domain was often incidental to what the paper was actually about. To address this matter, classification categories were inductively developed and refined while the papers were being studied. In a number of papers, there were multiple potential classification identifiers. For example, a study by Isabirye et al. makes contributions related to agriculture, e-commerce as well as user requirements elicitation (Isabirye, Flowerday, Nanavati, \& von Solms, 2015). Papers such as these had to be reread to reflect on where their main contribution lay. To make matters more interesting, several papers were found to have contributions that were under-emphasised by the authors - in the title, abstract or even contributions section.

The research categorisation that emerged is presented in Table 4. Since most of the papers that performed impact assessments also made contributions related to a process or method, the classification category of impact assessment or monitoring and evaluation (M\&E) was eventually merged with the method category.

The dominant research domains are method (including impact assessment and M\&E), access (including connectivity and telecentres), general business and SMEs. These domains account for $74 \%$ or 43 of the 58 papers. Education, health and agriculture also receive some attention, followed by isolated papers on e-government, crime prevention and Library and Information Science. In each of the research categories that contain six or more papers (i.e., method, access, general business, SMEs and education), there is at least one author with multiple papers in that category. The four broad domains of method, access, general business and SMEs will now be discussed in 
Table 4: Research domains of South African ICT4D publications

\begin{tabular}{lc}
\hline Research domain & No. papers \\
\hline Method: & \\
• Impact assessment / M\&E & 9 \\
• Other project processes or methods & 6 \\
Internet access / connectivity /telecentres & 10 \\
General business & 10 \\
SMEs / small business development & 8 \\
Education & 6 \\
Health & 4 \\
Agriculture & 2 \\
E-government & 1 \\
Crime prevention & 1 \\
Library and Information Science & 1 \\
\hline Total & 58 \\
\hline
\end{tabular}

more detail.

\subsubsection{Method/impact assessment}

The large focus on impact assessment/M\&E and other ICT4D project methods comes as an interesting surprise. Impact assessment papers range in scope from a study on the impact of ICT investment on human development across 51 countries (Bankole, Shirazi, \& Brown, 2011), to an evaluation of a particular project (van der Vyver \& Marais, 2015). Method contributions related to impact assessment or M\&E range from a high level critique on how ICT4D projects are evaluated (Gomez \& Pather, 2012), to the development of a more hands-on process assessment framework (Osah, Pade-Khene, \& Foster, 2013). General method or process related contributions include studies on project selection (Plauché, Waal, Grover, \& Gumede, 2010), user requirements elicitation (Mamba \& Isabirye, 2015), project management (Pade-Khene, Mallinson, \& Sewry, 2011), policy evaluation (Krauss, 2013), systems thinking (Turpin \& Alexander, 2014) and research philosophy (van Zyl, 2015).

As can be seen, a variety of topics and angles are covered. Most of the papers in this category move beyond their immediate project domains and make contributions on a meta-level, as part of a wider discourse with a research audience.

\subsubsection{Access}

"Access" is used here as an umbrella term for the provision of ICT facilities, including public access, telecentres and platforms such as the Digital Doorway (Stillman et al., 2011). In South Africa, telecentres and other public access facilities still serve an important role as mobile data remains expensive and ICT infrastructure as well as data coverage is still inadequate in some rural areas. Accordingly, public access is a core theme in the "access" category of South African ICT4D research. Examples include assessments of public access facilities (Chigona, Lekwane, Westcott, 
\& Chigona, 2011; Gomez, Pather, \& Dosono, 2012) and a study on the adoption of communal computing facilities among the urban poor (Chigona \& Licker, 2008). Other work includes a study on the potential of mobile internet to address social exclusion (Chigona, Beukes, Vally, \& Tanner, 2009) and a study on how people access the internet from their homes (I. Brown, Letsididi, \& Nazeer, 2009). The Digital Doorway is a South African innovation that provides sturdy, low maintenance information kiosks in disadvantaged communities across the country (Stillman et al., 2011). Its impact is evaluated in (van der Vyver \& Marais, 2015).

A reflection on the "access" literature shows that while meaningful work has been done in this area, the references are relatively dated. This means that it is possibly not a current research area any more.

\subsubsection{General business}

Most of the papers under "general business" concern themselves with ICT matters at South African corporates. Examples include: A survey of challenges facing South African Chief Information Officers (K. Johnston, Muganda, \& Theys, 2007), a survey of the impact of Black Economic Empowerment on IT Governance implementation (Mohapi \& Njenga, 2012), and a survey of knowledge management practices among South African firms (Naicker \& Omer, 2015). Other topics under the general business heading are trade (Bankole, Osei-Bryson, \& Brown, 2015) and banking (Motjolopane \& Lutu, 2011). The ICT4D concern of the business papers was not so much to promote socio-economic development, but rather to acknowledge the developing country context (A. Brown \& Grant, 2010).

\subsubsection{SMES}

The SME category concerns itself with the role of ICT in small business development. A typical paper is one that considers the effect of the use of ICT on the livelihood of micro-enterprises in Cape Town (Makoza \& Chigona, 2012). While most of the SME studies were situated in South Africa, there were two cross country studies, one of which investigates the impact of ICT usage on the profitability of SMEs across 13 African countries (Esselaar, Stork, Ndiwalana, \& Deen-Swarray, 2007).

\subsubsection{Conclusion}

To conclude, the South African ICT4D research landscape appears to have a unique characterisation of research domains, with a few strong central themes emerging from the analysis. The large occurrence of method related papers (in particular impact assessment), along with a waning number of access related studies, positions South Africa in the fourth wave of the ICT4D value chain (Heeks, 2014) for the survey period of 2006-2015. According to Heeks (2014), the ICT4D value chain consists of four waves or stages, namely readiness, availability, uptake and impact. These four waves are reflected in the changing emphasis of global ICT4D research over time. In particular, the third wave of ICT4D research (with an emphasis on uptake and access) took place 
from the mid-1990s to the mid-2000s. The fourth wave occurred from the mid-2000s to the mid2010s and was characterised by a focus on impact, as well as "intellectual consolidation" around methods and theories (Heeks, 2014). As can be seen from Table 4, the 'South African' research outputs fits well into the category of fourth wave ICT4D research.

\subsection{Research collaboration among institutions}

Incidences of co-authorship were used to investigate patterns of research collaboration within and among institutions. Only five of the 58 papers had a single author, indicating a strong preference by authors to work in a team (see Table 5). Of the 53 articles with multiple authors, 28 had two authors and 25 had three or more authors. Reasons for co-authorship may include supervisorstudent relationships as well as the possibility that articles report on projects executed by a team. However, this kind of information is not usually provided to the reader.

What is provided to the reader, is the institutional affiliation of authors, so that collaboration within and among institutions can be investigated. Of the 53 articles with multiple authors, 28 were co-authored by people who were all from the same institution (see Table 5). Seven had authors who were all South African but from different institutions within South Africa. Of these seven, five were from authors with institutions in the same geographical region. Eighteen of the articles that were co-authored, had among their authors, one or more with an international affiliation. Of the 18 articles that included international authors, only four had authors from more than one South African institution. The other 14 articles each had one South African institution involved, and in most cases (11 out of 14) one international affiliation. The international collaborators were from all over the globe, and no further trends were apparent pertaining collaboration between particular South African institutions and particular international institutions.

Table 5: Co-authorship and affiliation patterns of 'South African' ICT4D publications

\begin{tabular}{lcc}
\hline & Author status & No. papers \\
\hline $\begin{array}{l}\text { Single author } \\
\text { Co-authored: }\end{array}$ & 5 \\
& Two authors & 28 \\
& Three or more authors & 25 \\
\hline Muliple authors: & Single SA institution & 28 \\
& Multiple SA institutions, & 5 \\
& single region & \\
& Multiple SA institutions, & \\
& multiple regions & \\
\hline Multiple authors, one or more & & 14 \\
international co-authors: & Single SA institution & 4 \\
\hline Total & Multiple SA institutions & 53 \\
\hline
\end{tabular}


Overall, 41 out of the 53 papers with more than one author (77\%) had only one South African institution involved. The co-author institutional affiliation patterns indicate that the South African ICT4D authors firstly prefer to work with people from their own institutions, rather than with other South African institutions. Secondly, they would rather collaborate and publish with international partner(s) than with colleagues from elsewhere in South Africa. If co-authorship is an indication of research collaboration, then the institutional affiliation analysis indicates an alarming finding, namely that in ICT4D, collaboration among research institutions in South Africa (of the kind that that leads to international journal publications) is virtually absent.

\section{SUMMARY OF FINDINGS}

The analysis of the 58 'South African' ICT4D papers published over ten years in three prominent ICT4D journals has led to the following findings:

Of the three journals included in the survey, South African authors show a clear preference for publishing in EJISDC (37 of 58 papers). The growth in publications over the 10 year period is also the most pronounced in EJISDC. The previous analysis of EJISDC papers per country showed South Africa as the fourth most productive country by articles (Naudé, 2016a). Hence the relationship between South African authors and EJISDC goes both ways: EJISDC is popular among South African authors, and South Africa has a relative prominence at EJISDC.

The analysis per institutional affiliation indicates that UCT dominates the scene with 20 papers. UP is second with seven papers, closely followed by CPUT and Rhodes with six papers each. Of the three journals surveyed, UCT shows a preference to publish in EJISDC (with 14 out of their 20 papers). UCT has previously been identified as the most prolific institution publishing in EJISDC (Naudé, 2016b). Hence the relationship is again two ways: UCT prefers to publish in EJISDC and as a result they have also become prominent in EJISDC.

The analysis per geographical region shows two ICT4D publication hubs, namely the Western Cape (31) and Gauteng (25). Similarly, the Western Cape is the province with the highest empirical activity. However, over $50 \%$ of the papers with an empirical component reported on projects performed in areas beyond the location of the authors. Hence, the regions that benefitted from empirical activity were spread much wider than the Western Cape.

The classification of papers according to research domains showed some surprising results. More than a quarter of the papers reviewed (15 of 58) focused on method aspects - mostly impact assessment. These papers made ICT4D process related contributions beyond their immediate empirical domain. Access to ICT facilities was another prominent theme, although it is becoming a less current theme since most of the papers on access were published in 2012 or earlier. In the business category, the papers were almost equally spread between corporate business and SMEs. Smaller numbers of papers were found in the categories of education, health and agriculture.

The analysis of research collaboration among institutions shows a virtual lack of collaboration between research institutions in South Africa. Less than 10\% of the papers included in the review, had authors from multiple South African institutions. Authors appeared to prefer collaboration with an overseas counterpart rather than a South African colleague: 35\% of the papers in the study 
had at least one foreign author affiliation. What is also surprising is that research institutions in close geographical proximity (in particular the clusters in the Western Cape and Gauteng) seldom used the opportunity to collaborate with each other.

\section{CONCLUSION}

This paper assesses the ability of South African ICT4D researchers to provide research impact that is commensurate with their ICT4D project activities, particularly in terms of journal publications. A review was conducted of papers published by South African authors in three prominent ICT4D journals in the period 2006 - 2015. The review showed that a total of 58 papers were published during the ten year period. Fifty-eight is not an insignificant number and aligns with previous findings of South Africa's visible presence at ICT4D dissemination platforms, such as the IDIA and IFIP WG 9.4 conferences as well as the EJISDC journal. Judging by overall numbers, South Africans are performing well in publishing their ICT4D research. However, it was found that the publication of ICT4D papers is dominated by one institution in South Africa, and predominantly limited to one journal, namely EJISDC. The review further shows that, judging by co-authorship, there is a general lack of cooperation between research institutions in South Africa. A strength that was picked up during the analysis of research domains, was the large number of method related contributions. It appears that there are at least two areas of excellence in the surveyed papers that can and should be further leveraged, namely method/impact assessment and SME development.

The literature analysis provided a multifaceted assessment of the state of ICT4D publications by South African ICT4D researchers, and hence addressed the research question underlying the study. The final task that remains is to reconsider Geoff Walsham's remark, given the findings of the study. At the face of it, the overall number of 'South African' ICT4D publications in the three journals, as well as the wealth of their research contributions, are quite impressive and provides enough grounds to challenge Walsham's remark. However, the concerns highlighted in the study, such as one institution skewing the findings and the lack of collaboration between institutions indeed point to a lack of strategic thinking among South African ICT4D researchers overall. Further: while reading through the papers, instances were often found where the contribution of the paper was underemphasised by the authors and hence the authors were underselling themselvesmore evidence of lack of strategic thinking on how to achieve the best research impact by means of publications. Hence, while South African ICT4D research has clear strengths as well as potential for further recognition, there are areas of major concern and reason for self-reflection by the ICT4D community in South Africa.

This study was limited to a review of three dedicated ICT4D journals. While the selection of these journals were motivated in the research design, it remains a limitation as it does not acknowledge research outputs beyond these journals.

Future research is recommended to investigate the good research practices performed by UCT. Reasons for the general lack of collaboration between research institutions in South Africa needs to be investigated, especially since many of the institutions have geographically close neighbours. 
Another area to investigate further, is the research contributions of the 'South African' papers. The under-acknowledged areas with innovative contributions, such as the contributions related to methods, need to be further explored to ensure that they receive the recognition they deserve.

\section{References}

Andersson, A. \& Hatakka, M. (2013). What are we doing?: Theories used in ICT4D research. In 12th International conference on social implications of computers in developing countries, May 19-22, 2013, Ocho Rios, Jamaica (pp. 282-300).

Avgerou, C. (2010). Discourses on ICT and development. Information Technologies and International Development, 6(3), 1-18.

Bankole, F., Osei-Bryson, K.-M., \& Brown, I. (2015). The impact of Information and Communications Technology infrastructure and complementary factors on intra-African trade. Information Technology for Development, 21(1), 12-28. https://doi.org/10.1080/02681102. 2013.832128.

Bankole, F., Shirazi, F., \& Brown, I. (2011). Investigating the impact of ICT investments on human development. Electronic Journal of Information Systems in Developing Countries, 48(1), 1-19. https://doi.org/10.1002/j.1681-4835.2011.tb00344.x

Brown, A. \& Grant, G. (2010). Highlighting the duality of the ICT and development research agenda. Information Technology for Development, 16(2), 96-111. https://doi.org/10. 1080/02681101003687793

Brown, I., Letsididi, B., \& Nazeer, M. (2009). Internet access in South African homes: A preliminary study on factors influencing consumer choice. Electronic Journal of Information Systems in Developing Countries, 38(1), 1-13. https://doi.org/10.1002/j.1681-4835. 2009.tb00265.x

Chigona, W., Beukes, D., Vally, J., \& Tanner, M. (2009). Can mobile internet help alleviate social exclusion in developing countries? Electronic Journal of Information Systems in Developing Countries, 36(1), 1-16. https://doi.org/10.1002/j.1681-4835.2009.tb00254.x

Chigona, W., Lekwane, O., Westcott, K., \& Chigona, A. (2011). Uses, benefits and challenges of public access points in the face of growth of mobile technology. Electronic Journal of Information Systems in Developing Countries, 49(1), 1-14. https://doi.org/10.1002/j. 1681-4835.2011.tb00349.x

Chigona, W. \& Licker, P. (2008). Using diffusion of innovations framework to explain communal computing facilities adoption among the urban poor. Information Technologies $\& 5$ International Development, 4(3), 57-73.

Dodson, L., Sterling, S., \& Bennett, J. (2013). Considering failure: Eight years of ITID research. Information Technologies \& International Development, 9(2), 19-34.

Esselaar, S., Stork, C., Ndiwalana, A., \& Deen-Swarray, M. (2007). ICT usage and its impact on profitability of SMEs in 13 African countries. Information Technologies 8 International Development, 4(1), 87-100. 
Gallivan, M. \& Tao, Y. (2013). A longitudinal scientometric analysis of research published in IFIP 9.4 (2002-2013), In Proceedings of SIG GlobDev Sixth Annual Workshop, Milano, Italy, December 14, 2013 (Paper 12).

Ghosh, I., Mudavanhu, S., \& Belle, J. V. (2015). A critical evaluation of past IDIA research: Lessons learnt for IDIA and ICT4D researchers. In Proceedings of the 9th IDIA conference, IDIA2015, Nungwi, Zanzibar, 2015 (pp. 1-17).

Gitau, S., Plantinga, P., \& Diga, K. (2010). ICTD research by Africans: Origins, interests, and impact. In Proceedings of the 4th International Conference on Information and Communication Technologies and Development (ICTD),

Gomez, R. (2013). The changing field of ICTD: Growth and maturation of the field, 2000-2010. The Electronic Journal of Information Systems in Developing Countries, 58(1), 1-14. https: //doi.org/10.1002/j.1681-4835.2013.tb00408.x

Gomez, R. \& Pather, S. (2012). ICT evaluation: Are we asking the right questions? Electronic Journal of Information Systems in Developing Countries, 50(1), 1-14. https://doi.org/10. 1002/j.1681-4835.2012.tb00355.x

Gomez, R., Pather, S., \& Dosono, B. (2012). Public access computing in South Africa: Old lessons and new challenges. The Electronic Journal of Information Systems in Developing Countries, 52(1), 1-16. https://doi.org/10.1002/j.1681-4835.2012.tb00366.x

Heeks, R. (2010). An ICT4D journal ranking table. Information Technologies 8 International Development, 6(4), 71-75.

Heeks, R. (2014). Future priorities for Development Informatics research from the post-2015 development agenda. Last accessed 01 Jul 2018. Retrieved from http://hummedia.manchester. ac.uk/institutes/gdi/publications/workingpapers/di/di_wp57.pdf

International Development Informatics Association. (n.d.). Conferences. Last accessed 01 Jul 2018. Retrieved from http://developmentinformatics.org/conferences/index.html

Isabirye, N., Flowerday, S., Nanavati, A., \& von Solms, R. (2015). Building technology trust in a rural agricultural e-Marketplace: A user requirements perspective, Electronic Journal of Information Systems in Developing Countries, 70(1), 1-20. https://doi.org/10.1002/j. 1681-4835.2015.tb00504.x

ITWeb. (2016). Most SA consumers still wary of e-commerce. Last accessed. Retrieved from http://www.itweb.co.za/index.php? option=com_content\&view=article \&id =153744: Most-SA-consumers-still-wary-of-e-commerce \&catid $=69 \# 1$

Johnston, K. [K.], Muganda, N., \& Theys, K. (2007). Key issues for CIOs in South Africa. Electronic Journal of Information Systems in Developing Countries, 30(1), 1-11. https: //doi.org/10.1002/j.1681-4835.2007.tb00206.x

Johnston, K. [K.A.], Jali, N., Kundaeli, F., \& Adeniran, T. (2015). ICTs for the broader development of South Africa: An analysis of the literature. The Electronic Journal of Information Systems in Developing Countries, 70(1), 1-22. https://doi.org/10.1002/j.16814835.2015.tb00503.x

Krauss, K. (2013). Collisions between the worldviews of international ict policy-makers and a deep rural community in South Africa: Assumptions, interpretation, implementation, and 
reality. Information Technology for Development, 19(4), 296-318. https://doi.org/10. 1080/02681102.2013.793167

Makoza, F. \& Chigona, W. (2012). The livelihood outcomes of ICT use in microenterprises: The case of South Africa. Electronic Journal of Information Systems in Developing Countries, 53(1), 1-16. https://doi.org/10.1002/j.1681-4835.2012.tb00374.x

Mamba, M. \& Isabirye, N. (2015). A framework to guide development through ICTs in rural areas in South Africa. Information Technology for Development, 21(1), 135-150. https: //doi.org/10.1080/02681102.2013.874321

Mohapi, M. \& Njenga, K. (2012). Conceptualising the effect of the Black Economic Empowerment score-card on IT governance. Electronic Journal of Information Systems in Developing Countries, 54(1), 1-44.

Motjolopane, R. \& Lutu, P. (2011). Improving data quality in the banking supervisory data of Southern Africa central banks. Electronic Journal of Information Systems in Developing Countries, 50(1), 1-22. https://doi.org/10.1002/j.1681-4835.2012.tb00357.x

Naicker, V. \& Omer, N. (2015). Measurement and determining factors affecting the level of knowledge management. Electronic Journal of Information Systems in Developing Countries, 68(1), 1-20. https://doi.org/10.1002/j.1681-4835.2015.tb00494.x

Naudé, F. (2016a). Country trends and scholarly collaboration in the ICT4D research community 2000-2013: A single journal study. The Electronic Journal of Information Systems in Developing Countries, 72(1), 1-26. https://doi.org/10.1002/j.1681-4835.2016.tb00521.x

Naudé, F. (2016b). Electronic Journal of Information Systems in Developing Countries (20002013): A bibliometric study. The Electronic Journal of Information Systems in Developing Countries, 72(1), 1-23. https://doi.org/10.1002/j.1681-4835.2016.tb00520.x

Osah, J., Pade-Khene, C., \& Foster, G. (2013). Critical themes of process assessment in rural ICT4D projects: An analysis of assessment approaches, Electronic Journal of Information Systems in Developing Countries, 60(1), 1-22. https://doi.org/10.1002/j.1681-4835. 2014.tb00425.x

Pade-Khene, C., Mallinson, B., \& Sewry, D. (2011). Sustainable rural ICT project management practice for developing countries: Investigating the Dwesa and RUMEP projects. Information Technology for Development, 17(3), 187-212. https://doi.org/10.1080/02681102. 2011.568222.

Plauché, M., Waal, A. D., Grover, A. S., \& Gumede, T. (2010). Morphological analysis: A method for selecting ICT applications in South African government service delivery. Information Technologies 8 International Development, 6(1), 1-20.

StatsSA. (2017). Quarterly labour force survey: Quarter 2 2017. Last accessed. Retrieved from http://www.statssa.gov.za/publications/P0211/P02112ndQuarter2017.pdf

Stillman, L., Herselman, M., Marais, M., Boshomane, M., Plantinga, P., \& Walton, S. (2011). Digital doorway: Social-technical innovation for high-needs communities. Electronic Journal of Information Systems in Developing Countries, 50(1), 1-18. https://doi.org/10.1002/j. 1681-4835.2012.tb00352.x 
The World Bank. (2017). South Africa Overview. Last accessed. Retrieved from http://www. worldbank.org/en/country/southafrica/overview

Thompson, M. \& Walsham, G. (2010). ICT research in Africa: Need for a strategic developmental focus. Information Technology for Development, 16(2), 112-127. https://doi.org/10.1080/ 02681101003737390.

Turpin, M. \& Alexander, P. (2014). Desperately seeking systems thinking in ICT4D. Electronic Journal of Information Systems in Developing Countries, 61(1), 1-15. https://doi.org/10. 1002/j.1681-4835.2014.tb00435.x

van der Vyver, A. \& Marais, M. (2015). Evaluating users' perceptions of the Digital Doorway: A narrative analysis. Information Technology for Development, 21(1), 99-112. https://doi. org/10.1080/02681102.2013.841629

van Zyl, I. (2015). Disciplinary kingdoms: Navigating the politics of research philosophy in information systems. Electronic Journal of Information Systems in Developing Countries, 70(1), 1-17. https://doi.org/10.1002/j.1681-4835.2015.tb00501.x

Walsham, G. (2010). ICTs for the broader development of India: An analysis of the literature. The Electronic Journal of Information Systems in Developing Countries, 41(1), 1-20. https: //doi.org/10.1002/j.1681-4835.2010.tb00293.x

Walsham, G. (2017). ICT4D research: Reflections on history and future agenda. Information Technology for Development, 23(1), 18-41. https://doi.org/10.1080/02681102.2016. 1246406. 